\author{
Bernd W. Böttiger \\ Jan-Thorsten Gräsner \\ Maaret Castren
}

\section{Sudden cardiac death: good perspectives with this major health care issue}

Received: 16 April 2014

Accepted: 23 April 2014

Published online: 15 May 2014

(C) Springer-Verlag Berlin Heidelberg and ESICM 2014

B. W. Böttiger $(\varangle)$

Department of Anaesthesiology and Intensive Care Medicine, University Hospital of Cologne, Kerpener Straße 62, 50937

Cologne, Germany

e-mail: bernd.boettiger@uk-koeln.de

Tel.: +49 221 478-4807

URL: http://anaesthesie.uk-koeln.de/; http://www.grc-org.de; http://www.erc.edu

\section{J.-T. Gräsner}

Department of Anaesthesiology and Intensive Care Medicine, University Hospital Schleswig-Holstein, Campus Kiel,

Schwanenweg 21, 24107 Kiel, Germany

e-mail: graesner@eureca-one.eu

\section{Castren}

Department of Clinical Science and Education, Section of Emergency Medicine, Södersjukhuset, Karolinska Institutet, Stockholm, Sweden

e-mail: maaret.castren@ki.se

In Europe, it is estimated that 350,000 people are dying each year following sudden cardiac death with unsuccessful out-of-hospital cardiopulmonary resuscitation (OOH-CPR) [1]. This is almost 1,000 patients every day over the whole year. The same happens in the USA and in other industrialized areas of our world. Thus, sudden cardiac death is one of the leading causes of death in industrialized nations [1]. It is most probably the "killer number three" following cancer and other cardiovascular causes [2]. It is good to see that more and more studies and activities are being initiated to further elucidate and combat this problem [3]. One thousand deaths per daythis is as if two jumbo jets would crash every day during the whole year, without any survivors. If this would happen, would not we invest billions of euros, not only to search for victims and causes, but also to put an immediate stop to it?

Europe is not uniform. We know that we can find differences between nations, areas, and emergency medical service (EMS) systems. The overall incidences of sudden cardiac death with $\mathrm{OOH}-\mathrm{CPR}$ are reported to be between 30 and 120 per 100,000 inhabitants and year. The incidences of started CPR are lower: between 20 and 75 per 100,000 inhabitants and year (Table 1).

The overall survival rates are between $3 \%$ and more than $20 \%$ [4]. Bougouin and colleagues [5] now report the numbers and outcomes of the Greater Paris area over 2 years. The incidence of OOH-CPR (29 per 100,000 inhabitants and year) is rather low in their report, which may reflect low rates of start of CPR. In parallel, the bystander CPR before EMS arrival rate is rather high $(45 \%)$ and not so far away from the respective rates reported from the Netherlands and Scandinavian countries, where huge efforts have been undertaken in recent decades to improve survival following $\mathrm{OOH}$ cardiac arrest (OOH-CA) [6]. All this is very successful: for example, in Denmark, a threefold improvement in survival following $\mathrm{OOH}-\mathrm{CA}$ was noted over the 10 years of a recent study [7]. Taking into consideration the low incidence of OOH-CPR in the present study and the high bystander CPR rate accompanied by a mean EMS response time of $9.3 \mathrm{~min}$, the overall survival rate of $7.5 \%$ seems relatively low. This is one picture.

Another picture is that we get more and more information about incidences and survival following $\mathrm{OOH}-\mathrm{CA}$ in Europe and elsewhere [8]. This is excellent. And we get more and more comparative studies, comparing different nations, regions, systems etc. [9]. All this helps us to further improve care around "killer number three". The 
Table 1 Data from the first EuReCa paper [3]

\begin{tabular}{llllll}
\hline & Andalusia & Belgium & Germany & North Holland 2008 & Sweden \\
\hline Total population in the reported region & $5,575,128$ & $10,600,000$ & $5,622,667$ & $2,400,000$ & $9,000,000$ \\
OHCA considered for resuscitation & 1,102 & 5,671 & 2,267 & 1,433 & 59.71 \\
Incidence of OHCA considered for resuscitation/100,000 & 19.77 & 53.50 & 40.32 & 1,114 & 3,535 \\
Resuscitation started & 1,031 & 5,671 & 2,202 & 46.42 & 39.28 \\
Incidence of started resuscitation/100,000 & 18.49 & 53.50 & 39.16 & \\
\hline
\end{tabular}

next step on the way to a better understanding is the European Resuscitation Council (ERC)-supported by the European Society of Intensive Care Medicine (ESICM), the European Society of Cardiology (ESC), the European Society of Anaesthesiology (ESA), and the European Society of Emergency Medicine (EuSEM)initiative to combine and analyze data from existing European resuscitation registries [3]. The European Registry of Cardiac arrest (EuReCa) will come up with a 1-month survey of 20 national registries in October 2014. This study is called EuReCa-ONE and will show differences and opportunities for providing the best CPR for victims all over Europe (http://www.eureca-one.eu).

Milestones in improving survival following $\mathrm{OOH}-\mathrm{CA}$ are bystander CPR, telephone CPR by dispatcher, fast EMS response, hypothermia and temperature management, coronary revascularization, standard operating procedures, and the system approach. It takes a system to save lives [10-13]. We can see all this in Paris and elsewhere. And we can further improve.

The system starts at the layperson's level: $\mathrm{OOH}-\mathrm{CA}$ is witnessed in 60-80\% of cases, and the brain just needs 3-5 min of downtime to start to die. This is much faster than the EMS can arrive in almost all cases. Thus, the big picture and chance to further improve is the wife, the friend, the taxi driver, schoolchildren, and others.

Think big. We have seen this in Denmark and elsewhere, a blueprint for Europe and the world [7]: Schoolchildren's education is the way to go. A threefold improvement in survival cannot be achieved with any improvements in professional medical care.

This needs political engagement and political support. On 16 October 2013, 16-year-old Kea, who successfully resuscitated 12-year-old Nic some months ago-when waiting more than $10 \mathrm{~min}$ for the EMS-together instructed the European Commissioner of Health, Tonio Borg, how to successfully resuscitate. On 16 October 2013, we had the European Restart a Heart Day, and the motto was "Schoolchildren save lives."

The ERC, in an interdisciplinary and inter-professional campaign together with many other European organizations, suggests a European-wide educational program for schoolchildren CPR training. We know from several studies that we can start at the age of 12 years and earlier, that we need $2 \mathrm{~h}$ per year (we can take one out of biology and one out of sports), that teachers can do it following professional advice and education, and we all can and hopefully will help here. If the schoolchildren-like in Denmark and elsewhere [11] — do it every year, they will teach this to their family at home, and they will never forget. We will not only see the number of survivors of $\mathrm{OOH}-\mathrm{CA}$ increasing, we will also see social side effects. All who have ever seen schoolchildren learning CPR have seen the most enthusiastic and positive young people. They do not learn how to compete here, they learn to help each other. And a young boy from a social hot spot in Belgium-who initially did not want to participate in CPR training — said at the end of his training: "this was the first time for a long time that I was touching someone else without beating him immediately."

We also need to have more focus on the dispatching: if the dispatcher identifies cardiac arrest, the survival rate is much higher than if not; rapid dispatching saves lives [14]. Telephone CPR is a must. Details of this important link in the chain of survival were missing from the Greater Paris study. We hope that the SDEC registry will improve on this topic.

European-wide schoolchildren CPR training; telephone CPR by dispatcher; European-wide cardiac arrest registries; and legislation that not only requires the registration of each death by traffic accident, but it must also become a must to register $\mathrm{OOH}-\mathrm{CA}$. We can easily save 100,000 additional lives every year in Europe, 274 every day, and one every 5 min.

We are now living in an era of change. It is no longer the traffic accidents in most developed countries, after we have invested billions of euros over the recent decades to improve here; now it is sudden cardiac death. We must invest here now.

On 16 October 2014, we will have the second European Restart a Heart Day, and the motto in 2014 is "Saving loved ones." Everyone, every specialty, every profession, every system, every institution-and every school—are cordially invited to join in (www.erc.edu). 


\section{References}

1. Gräsner JT, Bossaert L (2013) Epidemiology and management of cardiac arrest: what registries are revealing. Best Pract Res Clin Anaesthesiol 27(3):293-306

2. Nichols M et al (2012) European Cardiovascular Disease Statistics 2012. European Heart Network, Brussels, European Society of Cardiology, Sophia Antipolis

3. Gräsner JT et al (2011) Quality management in resuscitation-towards a European cardiac arrest registry (EuReCa). Resuscitation 82(8):989-994

4. Berdowski J et al (2010) Global incidences of out-of-hospital cardiac arrest and survival rates: systematic review of 67 prospective studies Resuscitation 81(11):1479-1487

5. Bougouin W et al (2014) Characteristics and prognosis of sudden cardiac death in Greater Paris: population-based approach from the Paris Sudden Death Expertise Center (Paris-SDEC). Intensive Care Med. doi: 10.1007/s00134-014-3252-5
6. Herlitz J et al (2003) Factors associated with survival to hospital discharge among patients hospitalised alive after out of hospital cardiac arrest: change in outcome over 20 years in the community of Goteborg, Sweden. Heart 89(1):25-30

7. Wissenberg M et al (2013) Association of national initiatives to improve cardiac arrest management with rates of bystander intervention and patient survival after out-of-hospital cardiac arrest. JAMA 310(13):1377-1384

8. Nolan JP (2013) What's new in the management of cardiac arrest? Intensive Care Med 39(7):1211-1213

9. Gräsner JT et al (2011) ROSC after cardiac arrest - the RACA score to predict outcome after out-of-hospital cardiac arrest. Eur Heart J 32(13):1649-1656

10. Beylin ME et al (2013) Higher mean arterial pressure with or without vasoactive agents is associated with increased survival and better neurological outcomes in comatose survivors of cardiac arrest. Intensive Care Med 39(11):1981-1988
11. Lemiale $\mathrm{V}$ et al (2013) Intensive care unit mortality after cardiac arrest: the relative contribution of shock and brain injury in a large cohort. Intensive Care Med 39(11):1972-1980

12. Kamps MJ et al (2013) Prognostication of neurologic outcome in cardiac arrest patients after mild therapeutic hypothermia: a meta-analysis of the current literature. Intensive Care Med 39(10):1671-1682

13. Vaahersalo J et al (2013) Therapeutic hypothermia after out-of-hospital cardiac arrest in Finnish intensive care units: the FINNRESUSCI study. Intensive Care Med 39(5):826-837

14. Kuisma $\mathrm{M}$ et al (2005) Emergency call processing and survival from out-ofhospital ventricular fibrillation. Resuscitation 67(1):89-93 